\title{
O conto "A quase morte de Zé Malandro", de Ricardo Azevedo: a literatura infantil e juvenil e o cordel
}

\author{
The short story "A quase morte de Zé Malandro", by \\ Ricardo Azevedo: children's literature and chapbooks
}

\author{
El cuento "A quase morte de Zé Malandro", de Ricardo \\ Azevedo: la literatura infantil y juvenil y el pliego suelto
}

\footnotetext{
iD Sandra Trabucco Valenzuela

Faculdade de Tecnologia do Centro Paulo Souza (Fatec), São Paulo, SP, Brasil. E-mail: sandratrabucco@uol.com.br
}

Resumo: Estuda-se a relação entre a literatura popular e o conto "A quase Morte de Zé Malandro", da coletânea Contos de Enganar a Morte, de Ricardo Azevedo (2003), direcionada ao público infantil e juvenil. Apresenta-se um histórico geral da literatura popular que se expandiu a partir do século XV pela Europa, chegando ao Brasil, dentre outras formas, através da literatura de cordel de tradição portuguesa; destacam-se aspectos do cordel produzido no Brasil para, a seguir, analisar o conto de Azevedo.

Palavras-chaves: Literatura de cordel. Literatura infantil. Ricardo Azevedo. Cordel. Morte.

\begin{abstract}
This article studies the relationship between folk literature and the short story "A quase Morte de Zé Malandro", from the collection Contos de enganar a Morte, by Ricardo Azevedo (2003), directed to children. A general history of folk literature is presented, from how it spread since the 15th century across Europe, arriving in Brazil through the chapbooks
\end{abstract}


(cordel) of portuguese tradition; aspects of Brazilian-made chapbooks are outlined, and then Azevedo's short story is analysed.

Keywords: Chapbooks. Children's literature. Ricardo Azevedo. Folk literature. Death.

Resumen: Se estudia la relación entre la literatura popular y el cuento "A quase Morte de Zé Malandro", del libro Contos de Enganar a Morte, de Ricardo Azevedo (2003), direccionada hacia el público infantil y juvenil. Se presenta un histórico general de la literatura popular que se difundió a partir del siglo XV en Europa, llegando a Brasil en diversas formas, entre ellas a través de los pliegos sueltos de tradición portuguesa; se trabajan aspectos de los pliegos producidos en Brasil para, enseguida, analizar el cuento de Azevedo.

Palabras-claves: Pliegos sueltos. Literatura infantil. Ricardo Azevedo. Literatura popular. Muerte.

Submetido em 03 de agosto de 2020.

Aceito em 13 de novembro de 2020.

Publicado em 16 de julho de 2021. 


\section{A literatura popular: chapbooks, bibliothèque bleue, pliegos sueltos, literatura de cordel}

Entre os séculos XVI e XIX, ganham popularidade em toda a Europa os chamados "pliegos sueltos", "chapbooks" ou literatura de cordel, constituídos por folhetos impressos num formato pequeno, que coubessem num bolso.

Esses folhetos dispunham de uma grande variedade de títulos, com conteúdo e forma bastante diversificados: poemas, novelas de cavalaria, tratados políticos e religiosos, moralidades, lendas, receitas culinárias, narrativas infantis, almanaques, narrativas heroicas, magia para o amor e feitiços para a cura, obscenidades, além de histórias de horror e de acontecimentos sobrenaturais.

Constituídos por 8, 12, 16 ou 24 páginas e ilustrados a partir de xilogravuras, apresentavam baixo custo devido, na maior parte das vezes, à precariedade de sua matéria prima, considerando-se a baixa qualidade do papel e da impressão.

É difícil precisar como e onde surgiu a produção dos primeiros folhetos, contudo, sua disseminação acompanha a expansão das atividades tipográficas na Europa do século XVI. Na Península Ibérica, destacam-se as publicações do romanceiro popular e de novelas de cavalaria em versões de folhetos. O romance de cavalaria Amadís de Gaula, de García Rodríguez de Montalvo, publicado em Saragoça em 1508, que constitui uma das mais importantes obras da literatura espanhola, conquistou grande popularidade na Espanha também no formato de folhetos, batizados de pliegos de cordel, sueltos ou, ainda, pliegos sueltos?.

O romance relata a história de Amadís, um bravo conquistador e aventureiro que enfrenta, entre outros perigos, os mares habitados por criaturas fantásticas e assustadoras, como fazem crer os mapas e cartas geográficas da época, inspirados na mitologia clássica e na Odisseia, de Homero (HAURÉLIO, 2010, p. 13). No

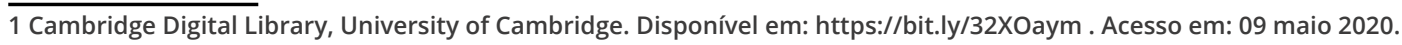


O conto "a quase morte de Zé Malandro", de Ricardo Azevedo: a literatura infantil... Sandra Trabucco Valenzuela

clássico estudo sobre os romances medievais, García de Enterría (1973, p. 23) sustenta que o nível cultural dos leitores dos pliegos de cordel obrigava os editores a selecionar e resumir trechos da obra de modo a torná-los o mais atraente possível, criando assim uma zona de intermediação que se situava entre a cultura culta e a popular, de caráter folclórico e tradicionalista:

Estos romances, difundidos la mayoría en pliegos sueltos, constituyen a su vez una nueva forma de lectura de los libros de caballerías, una fácil vía de acceso al género sobre todo en un sector de público de poca formación y escasos medios, incapaz quizás de otro modo de acercarse a estos libros. Así sucede, por ejemplo, con los cinco romances hasta ahora conocidos de Amadís, romances artísticos a juicio de algunos críticos, difundidos la mayoría de ellos en pliegos sueltos y fechados todos en la primera mitad del siglo XVI/(MARÍN PINA, 1997, p. 981)

Por sua vez, na Inglaterra, os folhetos ou chapbooks eram vendidos por vendedores ambulantes chamados de chapmen (em Língua Inglesa antiga, "chap" designa "comércio"). Segundo Hausman (2005), desde o início dos anos 1570, esses ambulantes não apenas circulavam pelas ruas das cidades, mas também viajavam por todo o país, carregando caixas com uma grande variedade de títulos, levando essas histórias às regiões mais remotas. Os chapbooks foram um importante meio de disseminação da cultura popular, em especial em zonas rurais, onde se tornaram um suporte essencial para a divulgação e preservação de costumes e tradições.

Já na França, a divulgação desses livros populares iniciou-se em 1602, com a família Jean Oudot, proprietária de uma editora em Troyes. Nicolas Oudot teve a ideia de imprimir obras menos volumosas que as edições dos impressores parisienses: 
O conto "a quase morte de Zé Malandro", de Ricardo Azevedo: a literatura infantil... Sandra Trabucco Valenzuela

reutilizando pranchas de origens diversas abandonadas com o triunfo do entalhe, utilizando caracteres já gastos, imprimindo sobre papel mediano fabricado pelos papeleiros champanheses, Nicolas Oudot edita a partir de 1602 livretos de baixo custo, logo designados "livretos azuis", em alusão à cor tanto do papel como da capa. [...] Os romances de cavalaria, com 21 edições, constituem cerca da metade dessa produção (CHARTIER, 2003, p. 117).

Desse modo, as obras populares passaram a ser conhecidas como Bibliothèque Bleue ou Biblioteca Azul. No entanto, os folhetos percorreram um caminho diferente, visto que sua difusão, de acordo com Chartier, ocorria sobretudo na cidade, tornando-se uma leitura compartilhada por toda uma sociedade (CHARTIER, 2003, p. 126), ao permitir a leitura textual e a leitura imagética, variando conforme o domínio da linguagem escrita.

Retomando a Península Ibéria, observam-se semelhanças entre os folhetos negociados na Espanha e em Portugal: os folhetos são exibidos ao público nos mercados populares ou em carretos de vendedores de rua amarrados por uma corda ou barbante, recebendo então o nome de "literatura de cordel". Segundo Abreu (2009), a primeira informação que consta a respeito da literatura de cordel em Portugal relaciona-se a Gil Vicente, que publicou algumas de suas peças nesse formato, como é o caso do texto Pranto de Maria Parda, que, por três séculos, continuou sendo divulgada em cordel (ABREU, 2009, p. 27)

De acordo com Câmara Cascudo (1939, p. 16, apud CURRAN, 2004 , p. 3), esses folhetos eram também conhecidos como "Literatura de Cego", devido à lei promulgada pelo Rei Dom João V, em 1789, que permitiu à "Irmandade do Menino de Jesus dos Homens Cegos de Lisboa" o direito de comercialização dessas obras. É durante o século XVIII que ocorre em Portugal um grande impulso desse recurso editorial, com a produção de textos originais, adaptações, traduções e reedições de séculos anteriores e uma grande variedade temática. Os autores não eram provenientes apenas 
O conto "a quase morte de Zé Malandro", de Ricardo Azevedo: a literatura infantil... Sandra Trabucco Valenzuela

das camadas populares, dentre eles havia advogados, professores, padres, militares, médicos, funcionários públicos, além de proprietários de tipografias, os quais, naquele momento, integravam a elite portuguesa. Se havia interesse pela produção desses textos, havia também interesse por sua leitura tanto por parte das camadas populares, como das classes médias (ABREU, 2009, pp. 41-46)

A chegada ao Brasil da literatura de cordel portuguesa firmou-se no século XVIII, com a remessa autorizada de livros e papéis por parte da Real Mesa Censória, criada por D. José, em 1768, e que atuou até 1826.

Se a diversidade temática constitui uma das marcas do cordel português que chegou ao Brasil, é possível afirmar que a representatividade do cordel no Nordeste apresenta algumas peculiaridades e marcas constitutivas que se reiteram na produção entre o final do século XIX e primeiras décadas do século XX, com forte marca da cantoria, desafios e construção poética popular: antes mesmo da divulgação impressa, as histórias eram cantadas em festejos e em momentos de diversão.

Temas recorrentes na literatura medieval tornam-se também presentes na literatura de folhetos nordestina: o monarca Ricardo Coração de Leão e sua defesa da Terra Santa, em 1189, e seu despótico irmão João Sem-Terra; Robin Hood; Carlos Magno; histórias do valente sertanejo que evocam as lendas da cavalaria; Roberto do Diabo (Robert the Devil), duque da Normandia; histórias de amor e bravura, de bandoleiros e do cangaço; narrativas de picardia e histórias extraordinárias como a do boi misterioso.

Curran (2014) descreve o folheto de cordel tradicional brasileiro como um impresso produzido com papel barato e frágil como o de jornal. A capa, que funciona também como folha de rosto, exibe o nome do autor, do editor (que adquire os direitos do autor) e do local e data de edição, embora nem sempre todas estas informações estejam presentes. Em geral, as gravuras ilustram a narrativa, porém, pode ocorrer que figuras conhecidas como atores de cinema e políticos estampem as capas, perdendo-se qualquer 
O conto "a quase morte de Zé Malandro", de Ricardo Azevedo: a literatura infantil... Sandra Trabucco Valenzuela

conexão com a história. Esse recurso é um apelo ao possível comprador que, mesmo sem capacidade leitora, poderá interessar-se pelo personagem apresentado (CURRAN, 2014, p. 5).

Figura 1 - Capa de folheto produzido em Recife.

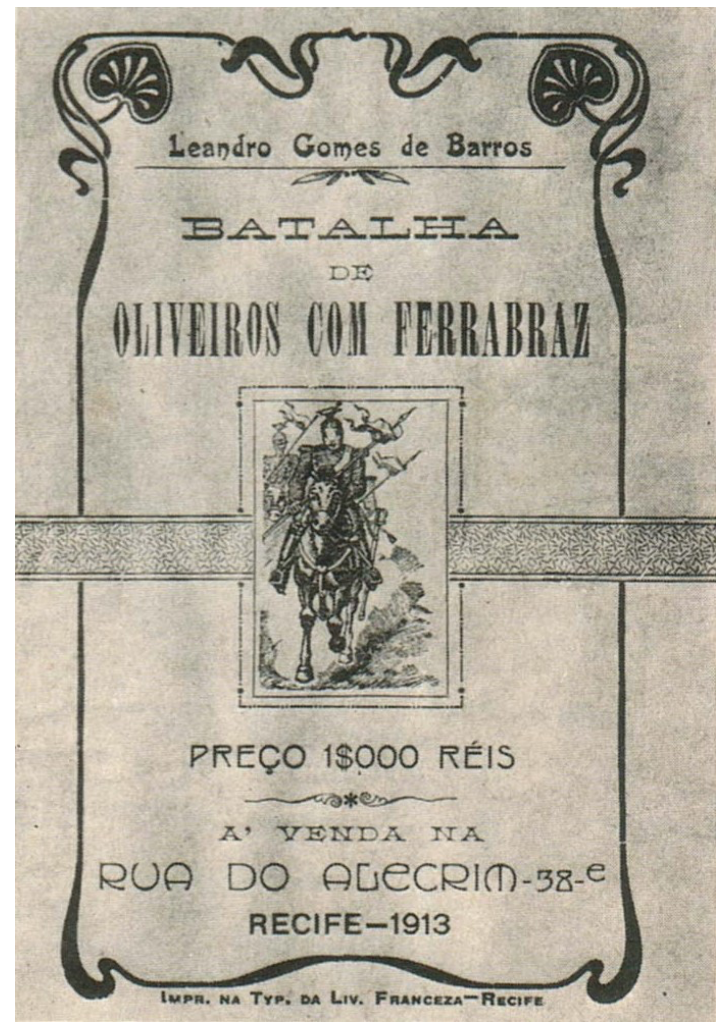

Fonte: BARROS, Leandro Gomes de. Batalha de Oliveiros com Ferrabraz, 1913.2

Repentistas, violeiros, cantadores e trovadores da poesia oral trouxeram para o cordel temas brasileiros, abordando temas religiosos, passagens e personagens históricos, episódios cotidianos, lendas e mitos, além de adaptações de temas tradicionais dos romances medievais do Ciclo Carolíngio, como a Batalha de Oliveiros com Ferrabraz, de Leandro Gomes de Barros (1865-1918), considerado o primeiro grande autor brasileiro de literatura de cordel e também o mais lido, com mais de 240 obras publicadas.

2 Disponível em: https://upload.wikimedia.org/wikipedia/commons/2/2c/Leandro_Gomes_de_Barros_obra_1913.jpg Acesso em 14 maio 2020. 
O conto "a quase morte de Zé Malandro", de Ricardo Azevedo: a literatura infantil... Sandra Trabucco Valenzuela

\section{Contos de enganar a morte: uma narrativa do fantástico}

Contos de enganar a morte, escrita e ilustrada por Ricardo Azevedo, é uma coletânea de quatro narrativas, que trata da chegada da morte, entendida como um espectro que ronda e visita as pessoas para levá-las da terra para o "outro mundo". Os contos - "O homem que enxergava a morte", "O último dia na vida do ferreiro", "O moço que não queria morrer" e "A quase morte de Zé Malandro" - relatam histórias de como lidar com a morte e tentar vencê-la, criando ardis e estratégias baseadas no jogo, na galhofa e na esperteza. A morte é personificada como uma mulher, que bate à porta e dialoga, negocia e faz tratos e troca de favores com os personagens, que, ao lado do narrador e do leitor, tornam-se cúmplices de uma narrativa fantástica, onde os fatos integram-se ao cotidiano - a morte torna-se comadre e madrinha protetora do sétimo filho de um dos personagens. A atemporalidade e o espaço não definido estão presentes em todas as histórias que compõem o livro, no entanto, são as ilustrações que marcam sua ligação com um ambiente de cunho mágico, identificado com paisagens e representações típicas do sertão brasileiro.

De acordo com Van der Linden (2018), o livro Contos de enganar a morte classifica-se como um livro com ilustração, pois difere do livro ilustrado por constituir-se de "um texto principal e relativamente poucas ilustrações em páginas isoladas" (VAN DER LINDEN, 2018, p. 12) e cujo texto é responsável por revelar a narrativa e sua geração de sentido.

Ao final do livro, o autor insere o texto "Conversa com Ricardo Azevedo" - na forma de um colofão - esclarecendo os motivos e as escolhas formais realizadas na construção da obra. Azevedo destaca a dificuldade de abordagem que o tema da morte apresenta quando direcionado ao público infantil: 
O conto "a quase morte de Zé Malandro", de Ricardo Azevedo: a literatura infantil... Sandra Trabucco Valenzuela

é preciso deixar claro, falar sobre a morte com crianças não significa entrar em altas especulações ideológicas, abstratas e metafísicas. Nem em detalhes assustadores e macabros. Refiro-me a simplesmente colocar o assunto em pauta. Que ele esteja presente, através de textos e imagens, simbolicamente na vida da criança. Que não seja ignorado. Isso nada tem a ver com depressão, morbidez ou falta de esperança. Ao contrário, a morte pode ser vista, e é isso o que ela é, como uma referência concreta e fundamental para a construção do significado da vida (AZEVEDO, 2003, p. 58).

A proposta, portanto, como ressalta Azevedo, é tratar a morte como mais um elemento que faz parte da vida e que, por isso, é preciso entender que, cedo ou tarde, ela virá, e conclui: “Crianças e jovens precisam aprender a lidar com a vida, da qual a morte é parte inseparável" (AZEVEDO, 2003, p. 59). Com base nessa proposta, Azevedo articula uma linguagem acessível, com personagens que dialogam de modo coloquial a respeito de uma temática que, a princípio, pode gerar rejeição justamente pela dor, ansiedade ou preocupação que possa causar, se tratada sem o devido cuidado.

A opção criativa, portanto, foi a adoção de um tom leve e jocoso, com o acompanhamento de ilustrações de cunho popular que também recordam, a exemplo da imagem da capa (Fig. 2), a festa tradicional mexicana celebrada no dia dos mortos, quando toda sorte de figuras da iconografia da morte arrebata espaços públicos e privados 3 . Observa-se, por exemplo, que o esqueleto da capa está posicionado entre uma árvore frutífera e uma palmeira, enquanto uma borboleta (símbolo da metamorfose) ocupa o canto superior direito e dois pássaros, sendo um claro pousa sobre um dos braços e outro escuro voa pela paisagem. A capa divide-se em dois grandes planos marcados pelo uso de claro e o escuro, enfatizando a dualidade vida x morte. Por outro lado, o claro da capa sugere o vazado da xilogravura em madeira e não a aplicação da

3 Esse tema foi abordado na animação Viva: a Vida é uma Festa (Coco), produção de 2017 da Pixar, com distribuição Walt Disney Studios. A narrativa do filme gira em torno de Miguel Rivera, um menino de 12 anos, que acaba indo para o mundo dos mortos por acidente; quando chega, ele procura pelo trisavô que o ajuda a retornar ao mundo dos vivos. 
O conto "a quase morte de Zé Malandro", de Ricardo Azevedo: a literatura infantil... Sandra Trabucco Valenzuela

cor branca ou qualquer outro tom pastel. O tronco do esqueleto associa-se ao tronco de uma árvore, e as mãos e braços são galhos dessa árvore frondosa, representação da árvore da vida, constituindo assim uma imagem que guarda o paradoxo vida e morte.

Figura 2 - Capa do livro, ilustração simulando xilogravura.

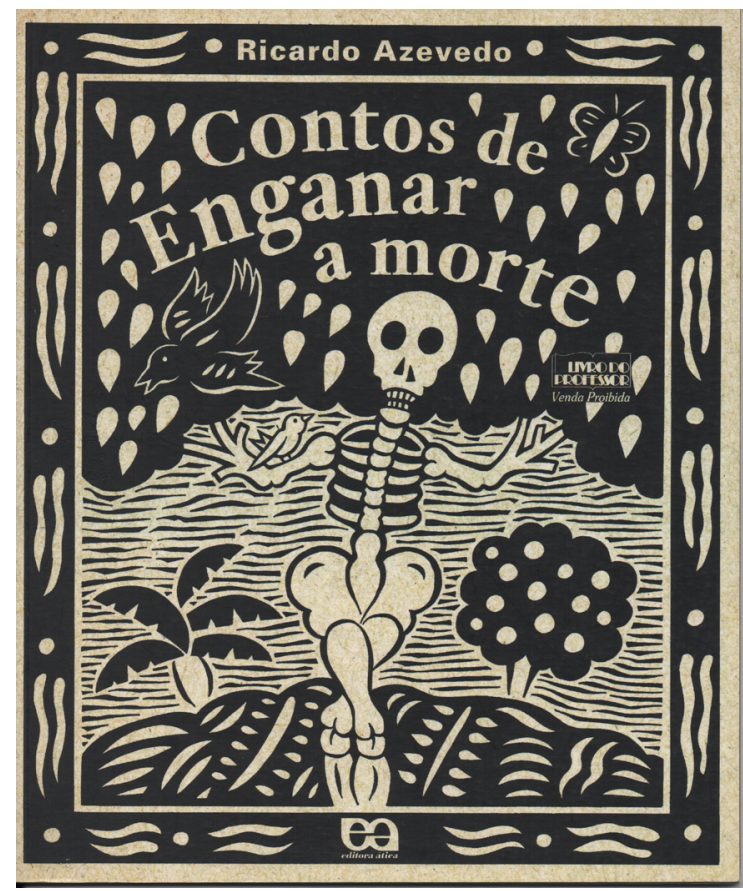

Fonte: AZEVEDO, R. Contos de enganar a morte. São Paulo: Ática, 2003.

Assim como na capa, inserem-se molduras coloridas nas três ilustrações de página inteira do conto "A quase morte de Zé Malandro". De acordo com Van der Linden, a função da moldura é delimitar e marcar uma representação, possibilitando a definição de "um espaço narrativo coerente, uma unidade dentro da narrativa por imagens" (VAN DER LINDEN, 2018, p. 71). Nesse caso, as molduras separam e destacam a ilustração da narrativa, reiterando seu diálogo com as ilustrações da literatura de cordel.

A quarta capa é independente da primeira e é utilizada pelo editor para dar pistas sobre o conteúdo da obra e sugerir outras leituras pertencentes ao autor, incluindo também a mesma ilustração inserida na folha de rosto, onde se observa um esqueleto 
O conto "a quase morte de Zé Malandro", de Ricardo Azevedo: a literatura infantil... Sandra Trabucco Valenzuela

sentado tocando viola, trajando terno, chapéu e botas, e acompanhado por um pássaro preto4, que é típico da região nordeste.

Para cada conto, o autor elabora três ilustrações coloridas; uma folha preta (frente e verso), com o respectivo título e ilustração pequena na página ímpar, além de uma ilustração como vinheta de encerramento. A folha de guarda, assim como a página de rosto, também apresenta pequenas ilustrações, constituindo vinhetas.

De acordo com o próprio Azevedo (2012), uma de suas principais fontes para a experimentação de uma linguagem pictográfica com trabalho em naquim e próxima ao cordel foram as xilogravuras do gravurista e artista plástico, o pernambucano Gilvan Samico (1928-2013). Nos termos de Azevedo, o desafio foi o de “compreender os recursos da xilogravura e transportá-los para o nanquim, de forma a jamais fazer qualquer coisa no desenho que não [fosse] possível de resolver vincando a madeira" (AZEVEDO, 2012, p. 8).

Figura 3 - Gravura DE Gilvan Samico.

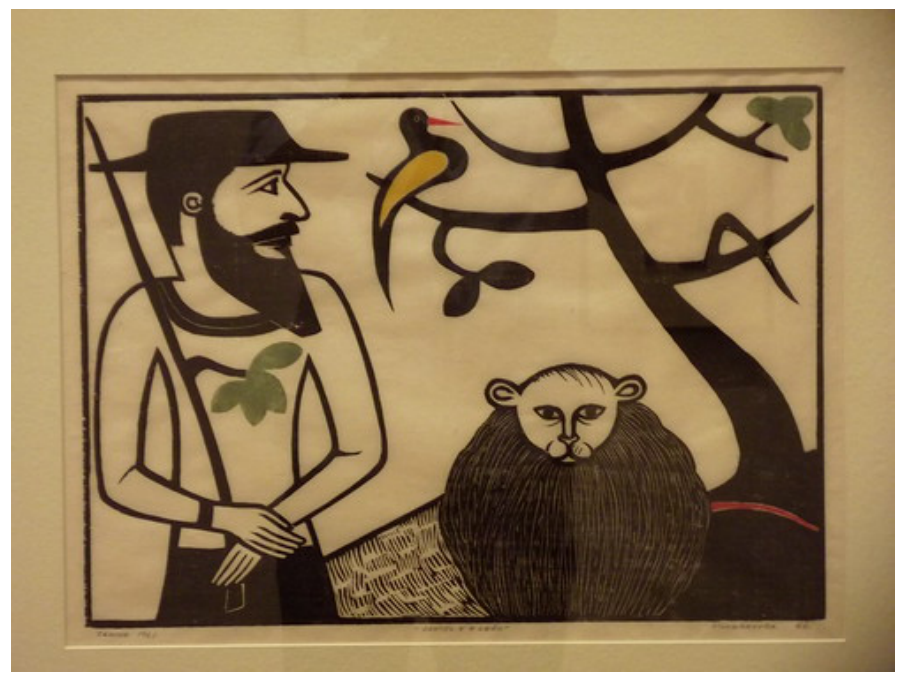

Fonte: https://live.staticflickr.com/7493/15590637339_c48f06d268.jpg Licenciado CC-BY-SA-NC.

4 Informações sobre o pássaro preto disponíveis em: https://www.portaldospassaros.com.br/passaro-preto-tudo-sobre-a-especie/ Acesso em: 12 dez. 2020. 
O conto "a quase morte de Zé Malandro", de Ricardo Azevedo: a literatura infantil... Sandra Trabucco Valenzuela

Medo, terror, horror povoam as narrativas orais das mais diversas sociedades, incorporando-se, ao lado de elementos míticos e narrativas heroicas e/ou históricas, conformando a ideologia de cada cultura.

Em O Horror sobrenatural em Literatura (2008), o escritor e teórico norte-americano H. P. Lovecraft sustenta que "a emoção mais antiga e mais forte da humanidade é o medo, e o tipo de medo mais antigo e mais poderoso é o medo do desconhecido" (LOVECRAFT, 2008, p. 13). Para ele, a sensação de medo desperta a satisfação no leitor, que compartilha, juntamente com os personagens, a emoção provocada pelo desconhecido, pelo espectro que espreita todo o tempo, buscando a oportunidade de agir. Essa multiplicidade de sentimentos entre medo e prazer, calafrios e tensão, alívio e novamente sobressalto é que explicam a permanência do gênero desde as narrativas primordiais.

Todorov, em seu Introdução à literatura fantástica (2012), discute o conceito de "fantástico", expondo proposições de diversos autores que tentam identificar temas recorrentes em narrativas do gênero: Dorothy Scarborough diferencia fantasmas modernos, o diabo e seus aliados e a vida sobrenatural; já Penzoldt apresenta a divisão fantasma, alma-do-outro-mundo, vampiro, lobisomem, feiticeiras e feitiçaria, o ser invisível e espectro animal; por sua vez, Vax compõe outra lista: "o lobisomem, o vampiro, as partes separadas do corpo humano, os distúrbios da personalidade, os jogos do visível e do invisível, as alterações da causalidade, do espaço e do tempo, a regressão" (TODOROV, 2012, p. 108-9).

Todorov discute a dificuldade de se precisar classes temáticas no âmbito do fantástico devido à multiplicidade em nível abstrato, ou seja, as tentativas de sistematização atuam mais como um catálogo de imagens ou etiquetas do que propriamente reflexões ao nível abstrato.

O conto "A quase morte de Zé Malandro" situa-se como uma narrativa de caráter fantástico-maravilhoso, ou seja, 
O conto "a quase morte de Zé Malandro", de Ricardo Azevedo: a literatura infantil... Sandra Trabucco Valenzuela

na classe das narrativas que se apresentam como fantásticas e que terminam por uma aceitação do sobrenatural. Estas são as narrativas mais próximas do fantástico puro, pois este, pelo próprio fato de permanecer sem explicação, não racionalizado, sugere-nos realmente a existência do sobrenatural. O limite entre os dois será então incerto; entretanto, a presença ou a ausência de certos detalhes permitirá sempre decidir (TODOROV, 2010, p. 58).

Em Contos de enganar a morte, as narrativas abordam temáticas relativas ao fantástico, ao sobrenatural, evidenciando a questão do medo, porém este é amenizado tanto através da linguagem e do tom jocoso, como das ilustrações. Ao longo do conto, o personagem Zé Malandro dialoga com instâncias sobrenaturais, inclusive com a personificação da morte, com o Diabo e sua esposa, sem qualquer estranhamento, como se fossem entidades presentes no cotidiano dos personagens e inclusive dos leitores, com os quais compartilha seus ardis.

Se para um adulto, o tom do diálogo mantido entre Zé Malandro e seus interlocutores não apresenta necessariamente a conotação de medo ou terror, é preciso pensar no receptor infantil e na abordagem do tema em questão: a morte. Como abordar um tema tão difícil com o leitor infantil? A escolha de Ricardo Azevedo foi associar o fantástico ao humor, recordando as palavras de Jacqueline Held (1980):

Mais que informação de tipo científico ou moralizante, o humor, especialmente o humor fantástico, é, em muitos casos, fonte de reflexão para a criança, elemento importante de sua formação intelectual e humana (HELD, 1980, p. 189).

\section{O enredo do conto "A quase morte de Zé malandro"}

Zé Malandro é um personagem jovem, astuto, folgado, malandro, a ponto de preferir passar o dia deitado na rede ou jogando 
O conto "a quase morte de Zé Malandro", de Ricardo Azevedo: a literatura infantil... Sandra Trabucco Valenzuela

baralho ao invés de trabalhar. Um dia, acolheu um velho viajante com poderes mágicos que, em agradecimento, concedeu-lhe quatro desejos: a) ser invencível no baralho; b) ter uma figueira e quem subisse nela só desceria com sua ordem; c) possuir um banco e quem se sentasse nele só sairia ao seu comando; d) ter um saco de pano que quem entrasse nele só sairia se ele assim o ordenasse.

Zé Malandro envelheceu tranquilo até que o dia em que a Morte bateu à sua porta para levá-lo, porém, ele a enganou, convencendo-a a conceder um último pedido: solicitou que a Morte subisse na figueira para apanhar um figo ao velho. Assim, devido ao desejo anterior, a Morte não conseguia descer de lá. Para deixar a figueira, a Morte concordou em dar a Zé mais sete anos de vida. Passado esse tempo, é o Diabo quem bate à porta de Zé para levá-lo, no entanto, ao sentar-se no banco, o Diabo lá permaneceu sem poder sair, como determinava o terceiro pedido. Casado, o Diabo resmungava que a esposa, a Diaba, não o perdoaria pela demora e por isso acabou fazendo um novo trato: outros sete anos de vida.

Passados os sete anos, o Diabo voltou, desta vez acompanhado da Diaba. Ao entrarem pela janela, ambos caíram dentro do saco e lá ficaram presos por um ano, apanhando todo dia, até que, cansado, Zé Malandro libertou os dois. Uma semana depois Zé Malandro foi para as profundezas do inferno. Entretanto, o Diabo o temia e São Pedro não o queria no Céu. Por isso, Zé Malandro acabou retornando para a Terra, onde dizem que continua invencível, jogando baralho.

\section{Contos de enganar a morte no esteio da literatura de cordel}

Ricardo Azevedo, de acordo com a "Biografia" inserida ao final de seu livro Contos de Enganar a morte, desde 1980 pesquisa a literatura infantil e suas raízes nas formas literárias populares, 
O conto "a quase morte de Zé Malandro", de Ricardo Azevedo: a literatura infantil... Sandra Trabucco Valenzuela

tomando "contos maravilhosos, adivinhas, quadras, anedotas, ditados e frases feitas do Brasil para recontá-las a seu modo" (AZEVEDO, 2003, p. 60).

Contos de enganar a morte é uma coletânea que toma de empréstimo modos e procedimentos da literatura de cordel, adaptando-os à produção destinada a crianças e jovens, inclusive em sua edição, isto é, embora seu projeto gráfico estabeleça um diálogo franco com o cordel, a obra consiste, na verdade, numa reorganização desses elementos através de suporte e qualidade pertinentes ao contexto do mercado editorial tradicional, com papel, impressão e acabamento refinado, que em nada lembram a precariedade dos folhetos de cordel tradicionais. No entanto, as histórias e suas ilustrações remetem à tradição popular.

Quanto à construção textual, pode-se considerar o livro como uma hipertextualidade com relação às narrativas orais e textos da literatura de cordel, ao se valer de mecanismos próprios de sua construção, seja do ponto de vista da estética visual, como de sua temática e linguagem. Trata-se, portanto, de uma especificidade, apontada por Genette, dentro do amplo conceito de intertextualidade, entendido como

\footnotetext{
uma prática do sistema e da multiplicidade de textos [...], o texto refere-se diretamente a textos anteriores, segundo modos de integração bem visíveis [...] numa estrita relação dos textos entre si (SAMOYAULT, 2008, p. 44).
}

O hibridismo de linguagens presente no livro permite a leitura das ilustrações associadas ao texto, numa narrativa que traz histórias guardadas na memória popular e que, por isso mesmo, encontra variantes no tempo e no espaço, mantendo, porém, seu tema principal: a chegada da morte.

O prefácio dos Editores se inicia com um questionamento logo no título - "você tem medo da morte?" — e prossegue confirmando que as histórias do livro chegaram ao Brasil pela mão dos portugueses e ganharam popularidade através da transmissão oral: 
O conto "a quase morte de Zé Malandro", de Ricardo Azevedo: a literatura infantil... Sandra Trabucco Valenzuela

Desde 1980 ele [Ricardo Azevedo] seleciona histórias contadas pelo povo brasileiro. [...] O trabalho de Ricardo é confrontar as diferentes versões e recontar, a seu modo, tentando sempre recuperar a essência de cada história. [...] O traço firme e grosso e mesmo a colocação das imagens dentro da página lembram muito a xilogravura de cordel e as pinturas primitivistas (AZEVEDO, 2003, p. 7-8)

Genette, em seu Palimpsestos: a Literatura de segunda mão (2006), considera a distinção entre dois tipos de práticas intertextuais, sendo a primeira uma relação de co-presença, quando um texto se faz presente no outro, e a segunda como uma relação em que um determinado texto recebe uma intervenção, transformando-se em outro, identificando-se como uma prática hipertextual: “hipertexto [é] todo texto derivado de um texto anterior por transformação simples [...] ou por transformação indireta: diremos imitação" (GENETTE, 2006, p. 16).

Os contos de Azevedo constituem um resgate da tradição oral, mas também uma reativação do sentido presente nesta reescrita direcionada ao público infantil e juvenil; entretanto, esta se despoja de expressões regionais, imprimindo à reescritura uma operação de transformação pragmática (GENETTE, 2006, p. 18), tendo em vista a fruição do leitor e seu domínio da linguagem coloquial, evitando marcas de variantes (PLATÃO E FIORIN, 1997, p. 112) diatópicas (falares regionais), diastráticas (variação entre grupos sociais) ou diacronismos (termos arcaicos), evitando, desse modo, elementos que podem comprometer ou dificultar a compreensão.

\section{Análise do conto}

Ao analisar semanticamente o título do conto, "A quase morte de Zé Malandro", temos a pista sobre o caminho traçado pelo personagem: como definir uma "quase morte"? Se Zé Malandro não morreu, portanto, continua vivo. Teria então havido a experiência 
O conto "a quase morte de Zé Malandro", de Ricardo Azevedo: a literatura infantil... Sandra Trabucco Valenzuela

da morte ou seria uma brincadeira desde o título? O título, por si só, perverte a dualidade vida versus morte, introduzindo um tom sarcástico e bem-humorado em função do nome do personagem. Zé driblou a morte, agarrando-se à vida com astúcia.

O narrador do conto apresenta-se como uma câmera, que, assumindo a terceira pessoa e de modo onisciente, revela a história através da sucessão de fatos e do discurso direto das personagens.

Todas as personagens são planas, pois assumem o aspecto de tipos: "As personagens planas eram chamadas temperamentos (humours) no século XVII, e são por vezes chamadas tipos, por vezes caricaturas. Na sua forma mais pura, são construídas em torno de uma única ideia ou qualidade" (FORSTER apud CANDIDO, 2011, p. 62).

No primeiro parágrafo da história, Zé é descrito pelo narrador como uma "boa pessoa, mas malandro", o que aponta para uma manipulação inicial do leitor em busca de empatia pelo personagem. Sua figura remonta aos personagens populares provenientes da tradição oral, assumindo o caráter arquetípico do trickster, isto é, protagonista que se relaciona com elementos mágicos, e que ao mesmo tempo congrega aspectos opostos: é heroico e destruidor, ingênuo e perspicaz, no caso do personagem, boa pessoa e malandro; trata-se de uma figura transgressora recorrente em mitologias, folclore e na literatura.

Em geral, os chamados tricksters podem apresentar formas variadas, como figuras antropomorfas, a exemplo das fábulas de Esopo, oferecendo explicações para a aparência de certos animais e fenômenos da natureza. Os animais comumente representados como tricksters são o coiote, o coelho, a raposa, o corvo e a tartaruga. Quando são propostos como figuras humanas, os tricksters singularizam-se por comportamentos jocosos, contestadores, irreverente e por vezes como figura bufa.

O trickster é o arquétipo do pícaro divino, ou seja, na mitologia, no folclore e na religião é um deus, espírito, homem/mulher ou ser antropomórfico capaz de alterar as regras das normas de com- 
O conto "a quase morte de Zé Malandro", de Ricardo Azevedo: a literatura infantil... Sandra Trabucco Valenzuela

portamento através de truques e embustes. Como exemplo de trickster está a figura de Loki, descrito na mitologia nórdica, como o deus da trapaça e da travessura, que pode assumir a forma que desejar. Loki possui um grande senso de estratégia, valendo-se de habilidades, intrigas e mentiras para alcançar seus objetivos. Embora ardiloso, Loki beneficia os deuses com seus criativos ardis, representando um desequilíbrio na perfeição do estabelecido.

O primeiro elemento mágico presente em "A quase morte de Zé Malandro" é a chegada de um viajante, um homem muito velho que recorda a figura mítica do Judeu Errante, personagem da tradição oral cristã. Camara Cascudo esclarece a respeito do "Judeu Errante":

Era sapateiro em Jerusalém, chamado Ahasverus, quando Nosso Senhor, com a cruz aos ombros, passou diante de sua tenda. 0 sapateiro deixou o trabalho para empurrar o Salvador, gritando: "Vai andando! Vai logo!". Nosso Senhor respondeu: "Eu vou e tu ficarás até a minha volta!". E o homem ficou, até hoje, andando pelo mundo, liberto da lei da morte, sem pressa e sem descanso. Espera o regresso do Senhor, que lhe deu a imortal penitência. A tradição nos veio de Portugal (CASCUDO, s/d, p. 494).

No conto, o velho viajante retribui a refeição oferecida por Zé Malandro com a concessão de quatro pedidos. Não há qualquer questionamento sobre quem é ou por que esse viajante tem poderes mágicos. Os desejos de Zé Malandro são aceitos, lembrando também a história de Aladim e a Lâmpada Maravilhosa, pertencente aos contos das Mil e Uma noites.

A relação que se estabelece entre o velho viajante e o mito do Judeu errante estabelece na narrativa a ideia de esperança que se confirma com a consumação dos quatro desejos, como sinal de bondade e retribuição, como se o velho estivesse num processo de aprendizagem imposto a ele como castigo por sua atitude.

O mito do Judeu Errante apresenta inúmeras versões que se perpetuaram na oralidade e na literatura. Nos termos de Ferreira (2000): 
O conto "a quase morte de Zé Malandro", de Ricardo Azevedo: a literatura infantil... Sandra Trabucco Valenzuela

\begin{abstract}
Um poeta romântico alemão, Schubardt, escreveu uma rapsódia lírica do judeu errante, traduzida por Gerard de Nerval, e em que o judeu errante é aproximado das noções de magia e de feitiçaria, o que também ocorre no mundo de nossa literatura de folhetos populares (FERREIRA, 2000, p. 4-5).
\end{abstract}

"Mas o tempo é invisível. Passa dia e noite e ninguém vê. A figueira virou uma árvore frondosa e Zé Malandro acabou ficando velho. Muito velho" (AZEVEDO, 2003, p. 48). Essa citação revela uma imprecisão temporal, considerando que não há um tempo histórico expresso na narrativa, mas um tempo interno medido pela idade do herói; um tempo que se dilui graças à sua imortalidade. O leitor observa a passagem do tempo através da imagem da figueira, que foi plantada como um pé de figo e se transformou numa árvore frondosa, enquanto Zé Malandro envelhecia. Foi então que, com a velhice, a Morte veio bater à porta.

A Morte é personificada de modo estereotipado, como sendo uma mulher ("dona Morte") de capa preta, segurando uma foice, impaciente, mal-humorada e de pouca conversa. Enquanto o viajante e, mais adiante, o Diabo recebem as respectivas ilustrações, a Morte não é representada por uma figura, prevalecendo a imagem estereotipada que o leitor constrói ou que já tem formada. A ausência da imagem da Morte permite manter certo suspense e medo do desconhecido. Por fim, ao ficar presa na figueira, a Morte viu-se obrigada a negociar mais sete anos de vida para Zé Malandro.

Ao negociar com a Morte e depois com o Diabo, Zé foi ganhando confiança, astúcia e, principalmente, tempo: esse tempo mítico conquistado não pode ser contado no relógio. Se pensarmos no mito do Fausto - personagem lendário, tantas vezes relido e transformado em personagem literário, que pactua com o demônio e vende sua alma para alcançar o conhecimento e levar a vida sem envelhecer -, temos um personagem que sofre o martírio e o castigo por esse acordo. Porém, Zé Malandro, em nenhum momento, se ressente ou sofre, pois sabe, como trickster que é, que ele vencerá, ludibriando todas as possíveis tentativas de enfrentar a morte física trazida pela persona Morte. 
O conto "a quase morte de Zé Malandro", de Ricardo Azevedo: a literatura infantil... Sandra Trabucco Valenzuela

Considerando que se trata de uma obra infanto-juvenil, vale destacar que o ato de morrer é encarado pela instância narrativa como necessário para a própria dinâmica da existência e, inclusive, da vida cotidiana. Como afirma o narrador, quando a Morte ficou presa, houve "desemprego, pois as pessoas não se aposentavam mais nem cediam lugar para as outras mais jovens. E o pior: a população começou a aumentar muito" (AZEVEDO, 2003, p. 51). Essas afirmações encontram eco nas palavras que encerram o livro e que oferecem uma leitura de aceitação da morte e valorização da vida:

não é preciso se preocupar com a morte. Ela é garantida e ninguém vai ser bobo de querer roubá-la da gente. O importante é cuidar da vida, que é boa, bela, rica, preciosa e inesperada, mas muito frágil. Ela, sim pode ser roubada (AZEVEDO, 2003, p. 62).

Ao conseguir enganar a Morte, Zé assume uma atitude de deboche e desdém. Sete anos depois, é a vez do Diabo aparecer para levá-lo. O Diabo é personificado como um homem estranho, de cara feia, e vestido de chapéu e paletó escuro, compondo um personagem lúgubre, sério e desconfiado, mas que teme a própria esposa. Porém, na ilustração, o Diabo é representado com chifres e uma longa cauda, muito diferente, portanto, do que o texto propõe. Sete anos mais tarde, o Diabo e a Diaba retornam em busca de Zé Malandro. A Diaba é personificada por uma muIher desconfiada, que não crê no marido, porém não há ilustração de referência, o que aguça a imaginação do leitor. Mais uma vez, Zé Malandro vence a morte, ao enganar o Diabo e a Diaba, que fogem apavorados.

Até então, todas as ações ocorreram na casa de Zé Malandro (cuja localização não é revelada); no entanto, com sua morte, a cena transferiu-se para o inferno e, a seguir, para o céu, moldando na imaginação do leitor o mesmo cenário de Céu e Inferno da religiosidade popular. A morte de Zé é narrada com um eufemismo que apresenta uma marca de falar regional, o qual é evitado 
O conto "a quase morte de Zé Malandro", de Ricardo Azevedo: a literatura infantil... Sandra Trabucco Valenzuela

ao longo do conto para evitar dificuldades de compreensão: "Zé fechou os olhos e entregou a rapadura". No Nordeste, a rapadura consiste num símbolo de resistência, trata-se de um elemento intimamente ligado à vida do sertanejo. A expressão "entregar a rapadura" é um eufemismo para a morte, no sentido de desistir da vida.

Coube a Zé Malandro encontrar o Diabo e São Pedro, porém, nenhum dos dois quis recebê-lo ou sequer ouvi-lo. Solitário e sem outra opção, Zé retornou à terra e continua "por aí, invencível, jogando seu baralhinho", isto é, Zé tornou-se um fantasma simplesmente por não ter aonde ir, assumindo o perfil de lenda. A ilustração final de Zé Malandro mostra o personagem tocando viola e cantando, como um cantor de folhetos de cordel, posicionado num cenário que remete a uma estilização da bandeira brasileira: o céu azul circular, com estrelas que se assemelham a cortinas num palco ou janela; o verde colocado na base colorindo a vegetação; a figura triangular que remete ao losango amarelo, além das nuvens brancas.

Figura 4 - Última imagem de Zé Malandro em Contos de enganar a morte.

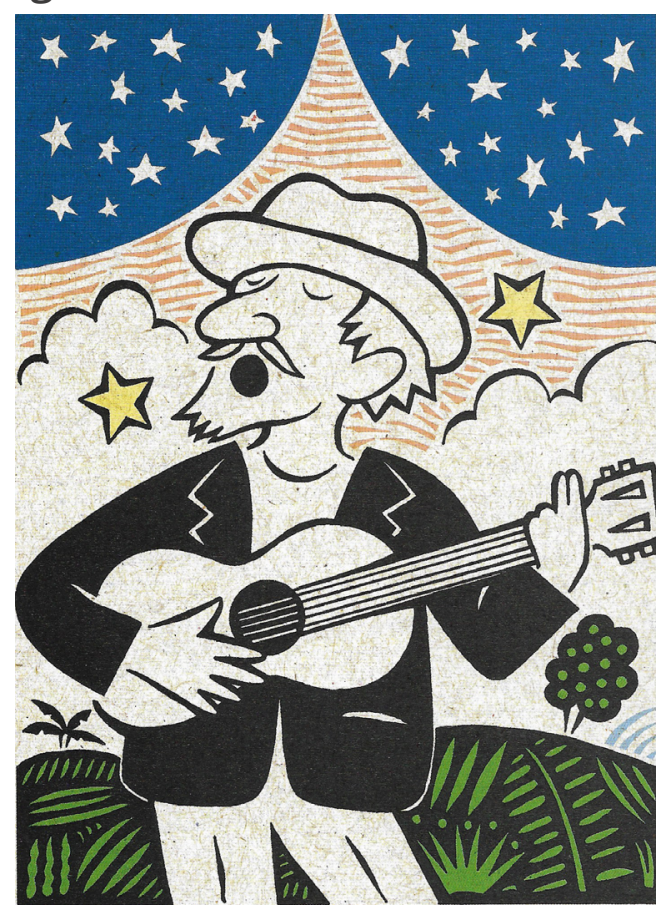

Fonte: AZEVEDO, Ricardo. Contos de Enganar a Morte. São Paulo: Ática, 2003. p. 55. 
O conto "a quase morte de Zé Malandro", de Ricardo Azevedo: a literatura infantil... Sandra Trabucco Valenzuela

No artigo "Literatura infantil: origens, visões da infância e certos traços populares" (1999), Ricardo Azevedo defende dez pontos de contato entre a literatura infantil e juvenil e o popular, são eles: 1. a recorrência do cômico (o riso, o deboche, a alegria e o escárnio); 2. a fantasia e ficção como modo de verificação ou experimentação da verdade; 3. personagens movidos mais pelos próprios interesses, pelo livre arbítrio, pela aproximação afetiva, pelo senso comum e pela busca da felicidade do que pela ética pré-estabelecida; 4. temas remanescentes de narrativas de iniciação em busca do autoconhecimento ou da identidade e luta do velho contra o novo; 5. personificações e antropomorfizações; 6 . a metamorfose; 7. poções, adivinhas, instrumentos e palavras mágicas; 8. histórias de heróis, sua iniciação e retorno modificado; 9. imagens recorrentes de voos mágicos, monstros, entre outros; 10 . o final feliz (AZEVEDO, 1999, p. 8).

Todos esses elementos elencados por Azevedo estão presentes em Contos de enganar a Morte, constituindo, portanto, um projeto de escrita no âmbito da literatura infantil e juvenil que está em conformidade com os parâmetros estabelecidos pelo próprio autor. A obra reordena mitos, aproximando-os ao cordel, ao popular, com o objetivo da fruição e não de uma literatura meramente moralizante ou pedagógica.

\section{Considerações finais}

Contos de enganar a Morte, de Ricardo Azevedo, constitui uma obra que resgata a tradição oral, reunindo narrativas que estão presentes em diversas culturas, perpassando o tempo e o espaço, através de temas que falam a pessoas de todas as épocas: vida e morte, amor, bem e mal, além de outras antíteses que compõe o cotidiano de todo ser humano. Nos termos de Azevedo: 
O conto "a quase morte de Zé Malandro", de Ricardo Azevedo: a literatura infantil... Sandra Trabucco Valenzuela

Através dos contos populares [...] temos a oportunidade de entrar em contato com temas que dizem respeito à condição humana vital e concreta, suas buscas, seus conflitos, seus paradoxos, suas transgressões e suas ambiguidades.

Na minha visão, os contos populares, independentemente de rótulos como "cultura popular", "folclore" e outros, podem ser considerados uma excelente introdução à literatura, pois nada mais fazem do que trazer ao leitor, de forma acessível e compartilhável, enredos, imagens e temas recorrentes na ficção e na poesia (AZEVEDO, 2007, p. 8).

Contos de enganar a Morte consegue ser, ao mesmo tempo, contemporâneo e tradicional, popular e inovador, devido à abordagem com que o tema da morte é tratado: com linguagem e humor atuais, o autor inova trazendo aspectos tradicionais e populares visíveis através das ilustrações e outros elementos gráficos. Em outras palavras, o tema, sua linguagem e a concepção das ilustrações formam um tecido complexo de elementos que dialogam e constroem uma hipertextualidade com o cordel tradicional, tomando de empréstimo suas práticas, e instigando o leitor a ampliar seu repertório, abrindo espaço para uma aproximação às narrativas e aos folhetos de cordel presentes ainda hoje na cultura popular.

\section{Referências}

ABREU, Márcia. Histórias de cordéis e folhetos. Campinas, SP: Mercado de Letras, 2009.

AZEVEDO, Ricardo. Conto popular, literatura e formação de leitores. 2007. Disponível em: http://www.ricardoazevedo.com.br/wp/wp-content/uploads/Contos-populares.pdf Acesso em: 05 nov. 2020.

AZEVEDO, Ricardo. Contos de enganar a morte. São Paulo: Ática, 2003. AZEVEDO, Ricardo. Ricardo Azevedo: Entrevista. 2012. Disponível em: http://www.ricardoazevedo.com.br/wp/wp-content/uploads/2012-Entrevista-Livro-Trac\%CC\%A7o-e-Prosa.pdf Acesso em 14 dez. 2020. 
O conto "a quase morte de Zé Malandro", de Ricardo Azevedo: a literatura infantil... Sandra Trabucco Valenzuela

AZEVEDO, Ricardo. Presença Pedagógica. Dimensão, Belo Horizonte, n. 27, maio/jun. 1999. Disponível em: http://www.ricardoazevedo.com.br/wp/wpcontent/uploads/Literatura-infantil.pdf Acesso em: 03, ago., 2020.

CAMBRIDGE DIGITAL LIBRARY, University of Cambridge. Disponível em: http://cudl.lib.cam.ac.uk/collections/spanishchapbooks/1 Acesso em: 19, jul., 2020.

CANDIDO, Antonio et al. A personagem de ficção. 12 ed. São Paulo: Perspectiva, 2011.

CHARTIER, Roger. Leituras e leitores na França do Antigo Regime. Trad. Álvaro Lorencini. São Paulo: Unesp, 2004.

CURRAN, Mark J. Relembrando a velha Literatura de Cordel e a voz dos Poetas. USA: Trafford, 2014.

FERREIRA, Jerusa Pires. O Judeu Errante: a materialidade da lenda. Revista Olhar UFSCar, Santa Catarina, ano 2, n. 3, jun. 2000. Disponível em: http:// www.ufscar.br/ revistaolhar/pdf/olhar3/02Jerusa.pdf Acesso em 01 set. 2020

GARCÍA DE ENTERRÍA, María Cruz. Sociedad y poesía de Cordel en el Barroco. Madri: Taurus, 1973.

GENETTE, Gerard. Palimpsestos. A literatura de segunda mão. Belo Horizonte: Faculdade de Letras/UFMG, 2006.

HAURÉLIO, Marco. Breve história da literatura de cordel. São Paulo: Claridade, 2010.

HAUSMAN, Nicholas. Chapbook analysis. MIT Projects, 2005. Disponível em: https://ocw.mit.edu/courses/history/21h-418-from-print-to-digitaltechnologies-of-the-word-1450-present-fall-2005/projects/ Acesso em: 30, jun., 2020.

HELD, Jacqueline. 0 imaginário no poder: as crianças e a literatura fantástica. 2 ed. São Paulo: Summus, 1980.

LOVECRAFT, H. P. O horror sobrenatural em literatura. São Paulo: lluminuras. 2008.

MARÍN PINA, María del Carmen. Romancero y libros de caballerías más allá de la Edad Media. In: LUCÍA MEGÍAS, José Manuel. Actas del Congreso 
O conto "a quase morte de Zé Malandro", de Ricardo Azevedo: a literatura infantil... Sandra Trabucco Valenzuela

Internacional de la Asociación Hispánica de Literatura Medieval. T. II. Universidad de Alcalá de Henares/Nuevo Siglo, 1997. Disponível em: http:// www.ahlm.es/IndicesActas/ActasPdf/Actas6.2/18.pdf Acesso em: 03, ago., 2020.

PLATÃO; Francisco; FIORIN, José Luiz. Lições de texto: leitura e redação. 2 ed. São Paulo: Ática, 1997.

PORTAL DOS PÁSSAROS. Disponível em: : https://www.portaldospassaros. com.br/passaro-preto-tudo-sobre-a-especie/ Acesso em: 12 dez. 2020.

RODRÍGUEZ DE MONTALVO, García. Amadís de Gaula. Los cuatro libros. South Carolina, EUA: Createspace Independent Publishing/Amazon, 2014. SAMOYAULT, Tiphaine. A intertextualidade. Trad. Sandra Nitrini. São Paulo: Aderaldo \& Rothschild, 2008.

SAMICO, Gilvan. In: ENCICLOPÉDIA Itaú Cultural de Arte e Cultura

Brasileiras. São Paulo: Itaú Cultural, 2020. Disponível em: http:// enciclopedia.itaucultural.org.br/pessoa10514/gilvan-samico. Acesso em: 16 dez. 2020.

TODOROV, Tzvetan. Introdução à literatura fantástica. São Paulo: Perspectiva, 2012.

VAN DER LINDEN, Sophie. Para Ler o Livro Ilustrado. São Paulo: Senai, 2018. 